\title{
Samfundet som teater - Fra Caesar til Silvio
}

\author{
Af Hans Bonde
}

Det folk som tidligere gav magtbeføjelser til konsuler, legioner og alt andet, er nu faldet så dybt, at det kun begarer to ting: Panem et circenses (brod og skuespil)

Juvenal, 130 e.Kr.

I denne tid er vi vidne til endnu et kapitel $\mathrm{i}$ tendensen til teatralisering af politikken. Folket vil repræsenteres af skuespillere fremfor ukarismatiske tørvetrillere med politisk indsigt. Den tidligere Mr. Universe i bodybuilding, actionhelten Arnold Schwarzenegger gjorde B-filmskuespilleren Ronald Reagan kunsten efter og vandt valget $i$ ét af verdens rigeste samfund Californien. Valget af Arnold Schwarzenegger er langt fra en kuriositet i demokratiernes historie, men peger på langsigtede problemer i de parlamentariske systemers evne til at håndtere udfordringen fra populistiske stjerner, der byder befolkningen brød og skuespil frem for demokratisk dialog.

Forfatteren Darrell West har i bogen »Celebrity Politics « ${ }^{1}$ vist, hvordan en del af Schwarzeneggers populistiske tiltrækningskraft kommer fra, at han ligner sine vælgere ved tilsyneladende ikke at være »besmittet « af de politiske partiers pamperi. Celebritetspolikerne er sædvanligvis dygtige til at viderebringe meddelelser til almindelige mennesker i et letfatteligt og direkte sprog. Skuespillere og sportsfolk har været vant til at tackle medierne og nogle af dem har et særdeles godt greb om kommunikation ikke mindst gennem kropssproget. Kongresmedlem Sony Bony (Chers fraskilte og afdøde mand) satte sig ikke mange spor i amerikansk politik. Omvendt havde Ronald Reagan stor succes ikke mindst pga. sin ligefremhed, sin ærlige fremtoning og sine letfattelige, emotionelle budskaber f.eks. om USSR som ondskabens imperium. Det var sandsynligvis ikke mindst pga. disse kvaliteter, at den amerikanske befolkning gav Ronald Reagan en nærmest kultisk begravelse i juni 2004.

Hvor det i USA er skuespillere og sportsfolk, der går ind i politikken, er det i Italien omvendt politikerne, der giver befolkningen skuespil i stedet for politisk meningsudveksling. Når man ikke blot kan se udviklingen i Italien som et harmløst særtilfælde, skyldes det, at landet og ikke mindst Rom gennem historien har været norm- og formgivende for koblingen mellem æstetik og politik. At forestillingen om samfundet som en scene vandt frem i den græsk-romerske kulturkreds kan ikke undre, da selve teatret stammer fra det græske theatron, skueplads. For den romerske aristokrat var livet en stor scene. Som Peter Ørsted i sin fremragende Caesarbiografi $^{2}$ og Florence Dupont i sin bog om den romerske borgermand på republikkens tid har vist, gjaldt det om gennem krigsduelighed, retorisk håndelag og vel- 
gørenhed at erobre stadig højere poster i det politiske liv. Den fri romerske overklassemand var i modsætning til slaven, barnet og kvinden karakteriseret ved at bære en »toga virilis « som symbol på det legeme, der kunne og skulle tone manifest frem i offentligheden ved at have et »caput «, hoved, som symbol på den verbale overtalelseskunst samt ved at have en »manus «, hånd, som tegn på ejendomsret. ${ }^{3}$ Det er ikke noget tilfælde, at ordet »idiotes « på græsk oprindelig betød en »privatperson «; ikke at træde frem på den offentlige rampe og kæmpe om ære markerede en umandig tilbagetrækning fra samfundslivet karakteristisk for ignoranter.

Det centrale middel i folkeforførelsen var retorikken. Den notorisk dybt forfængelige Caesar hyrede nogle af romerrigets bedste retoriklærere for at opnå den formidable overbevisningsevne, der bestod i med krop, gestikulationer og verbal billeddannelse at tryllebinde mange hundreder på én gang uden brug af mikrofon. ${ }^{4}$

For den fri, romerske mand af senatorstand var det vigtigste ikke investeringer og ophobning af penge, men akkumulation af ære ofte opnået gennem en svimlende gældsætning. ${ }^{5}$ Målet var at opnå støtte gennem en $\varnothing$ dselhed, der demonstrerede, hvad befolkningen kunne forvente sig af underholdning og materielle gaver, når først velgøreren var blevet valgt ind $i$ et højere embede. Hellere $\varnothing$ konomisk ruin end manglende ærefuldhed. Caesar fejrede i år 46 f.Kr. sin sejr over sine interne modstandere i Romerriget med festligheder i en hidtil uhørt målestok. Enorme penge-, kød- og korngaver blev givet til undersåtterne, og diktatoren gav to gange gratis morgenmad til den romerske befolkning. Der arrangeredes hestevæddel $\varnothing \mathrm{b}$ og sportsstævner, to kampscener med flere hundrede deltagere, én på land og én til vands på en til lejlighe- den udgravet kunstig sø. I fem dage var der dyrekampe i arenaen. ${ }^{6}$ Caesars efterfølger Augustus gik endnu videre og efterlod sig efter eget udsagn en by i marmor og indledte en tradition med teatre, biblioteker, søjlegange, torve og statuer ikke mindst på sit eget forum. ${ }^{7}$

Med til det romerske koncept hørte en urbaniseringspolitik, hvor en romersk by først blev til en by, når der var oprettet et forum, et tempel, et termeanlæg (offentligt bad), en væddeløbsbane og en gladiatorarena. Hermed blev kejserkultens æstetik og drama tilbudt de undertvungne folkeslag som kompensation for afgivelsen af suverænitet ikke mindst i den østlige del af Romerriget, hvor kejserne blev forgudet.

I kejsertidens Rom blev den græske antikke sport mellem frie ligemænd forvandlet til en underholdningsindustri med det formål at passivisere de oprørske plebejiske masser og få dem til at føle sig som en del af det romerske imperiums elite. Fronto skriver om kejser Trajan, at: »Han vidste tydeligvis, at de to vigtigste midler til at bevare kontrollen med romerne, er kornuddelinger og skuespil, og at ens succes som kejser beror lige så meget på forlystelser som på alvorligere ting . $^{8}$

I stedet for en vis indflydelse via republikkens folkeforsamlinger og et magtfuldt romersk senat blev Roms frie borgere stopfodret med oplevelser såsom gladiator- $\mathrm{og}$ dyrekampe, hvor stemningen fra de storslåede sejre kunne gengives ved at lade barbarerne slås mod hinanden. I modsætning til den relativt demokratiske athenske bystat blev borgerne i en hellinistisk storby som Rom forvandlet til tilskuere og fremmedgjort for staten og dens førelse. Med Lewis Mumfords kritiske karakteristik blev storbyen en »container for spectators «. ${ }^{9}$ Fra Augustus' dage til år 200 e.Kr. steg antallet af fri- og festdage med under- 
holdning fra 93 til 175, og her er de ekstraordinært arrangerede spil ikke medregnet. Skønt de rige også langt hen ad vejen blev reduceret til passive tilskuere til kejserkulten, markerede de deres klasse ved en besættelse af titler og statussymboler. Den kulturelle overlegenhed markeredes i $t \varnothing j$, accent og gestikulationer og i en foragt for de socialt svage.

I de mange arenaer ikke mindst i den vestlige del af imperiet kunne tilskuerne nyde menneskets sejr over den farlige, vilde natur, hvilket skal tages helt bogstaveligt, da dyrekampene truede med at udrydde en del dyrearter, der blev importeret $\mathrm{i}$ rigt mål fra fjerne egne i Asien og Afrika. ${ }^{10}$ I Colosseums fine travertinarkitektur kunne folket føle en indflydelse på kejserens dispositioner gennem hans reaktion på folkestemningen, når den imperiale tommelfinger skulle vendes opad eller nedad i det pseudodemokratiske show. Cicero udtrykker det på den måde, at vox populi, folkets stemme, kan høres i arena og cirkus, og ofte startede politisk uro netop her. Og Tertullian tilføjer, at demonstrationer i cirkus måtte henregnes til folkets naturlige rettigheder, som hverken »sparer kejser eller borger «. Så brændende ønskede (den psykopatiske og incestuøse kejser i filmen Gladiator) Commodus sig folkets gunst, at han til sidst helt uhørt for en caesar selv steg ned i arenaens sydende gryde for med egen krop som indsats at gøre sig fortjent til folkets loyalitet. Han blev myrdet $i$ år 192 e.Kr. på en gladiatorskole, hvor han trænede til næste dags kamp i arenaen. ${ }^{11}$

Under Colosseums trægulv var der placeret en gigantisk underjordisk konstruktion i flere etager, så løver og tigre, kunstige skove og andre tableauer kunne skydes op til publikums forbløffelse i denne dødsdramaturgi. Når gladiatorkampene blev så populære, at kæmperne kunne blive idoler og sexsymboler, skyldtes det, at de, trods deres lavstatus i reglen som slaver, stillede sig frem på scenen og spillede deres rolle, kort sagt døde med ære. Deres fantastisk flotte udrustninger har været en del af dette højæstetiske gallashow for voyeurer af begge køn og alle stænder. Nederst tæt på begivenhederne sad kejseren og senatorerne, Øverst sad slaver og kvinder, dog ikke under den stoiske kejser Augustus, der forbød kvinderne adgang til dette mandeshow. ${ }^{12}$

På hestevæddeløbsbanen kunne de entusiastiske fanskarer holde med det blå eller det grønne hold med en fanatisme, der ikke lader moderne fanskarer noget efter. Som Plinius den yngre sagde om datidens tifosi (italienske tilskuere): »Deres loyalitet klæber alene til et stykke farvet stof $\ll .{ }^{13} \mathrm{~L} \emptyset$ bene blev ikke mindst spektakulære ved, at de mange små og lette vogne ofte stødte sammen, og da hestetøjlerne var bundet rundt om livet på vognstyreren, gjaldt det bare om at få skåret lædersnorene over med den kniv, der var en del af udrustningen, hvis man ville undgå at blive slæbt ihjel. På Cirkus Maximus i Rom kunne måske 200.000 begejstrede mennesker følge dette oldtidens Formel 1 sammen med kejseren, der havde direkte adgang til sin loge fra kejserpaladset på Palatinerhøjen. At væddeløbsbanen potentielt var et mødested mellem folk og kejser viser oprøret på cirkus i 190 e.Kr., hvor befolkningen fik presset kejser Commodus til at ofre sin øverste rådgiver Cleander på baggrund af en mistanke om, at Cleander havde hamstret korn for at profitere på kornmanglen. ${ }^{14}$ Kejserne, der betragtede sig som patroner for plebejerne, var faktisk ofte villige til at ofre deres rådgivere og nærmeste embedsmænd, når gemytterne under lege og spil kogte over i desperation over manglen på fødemidler.

I det $\varnothing$ stromerske område overlevede 


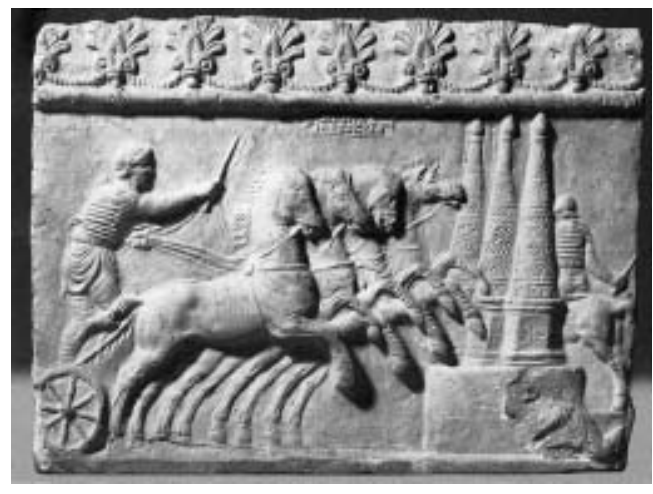

Relief fra begyndelsen af det første århundrede efter Kristi fødsel. En firehestes vogn narmer sig et sving på vaddeløbsbanen.

hestevæddeløbene ind i den tidlige middelalder. De grønne og blå's fanskarer blev mere og mere politiserede, og deres »hooligans « kæmpede mod hinanden i voldsomme gadekampe. I 532 e.Kr. fandt de dog fælles fodslag i et oprør mod kejser Justinian, der druknede revolten i blod og brugte den som anledning til en opstramning af den absolutistiske styreform. ${ }^{15}$ Koblingen mellem sport og politik er ikke nogen ny opfindelse, men fandt altså sted i den europæiske civilisations vugge.

I de enorme og pompøse kejserlige badeanlæg spredt ud over imperiet kunne befolkningen skabe en ren og velplejet romersk krop distinkt anderledes end de ildelugtende og behårede barbarer, og efter et par timers bad, massage, klipning, fitness, læsning, bøn og snak med ligesindede, iklæde sig det stilfulde maskuline værdighedstegn togaen. Alene Caracallas termeanlæg i Rom, der var det næststørste med dets 11 hektar, kunne lukke 6-8000 gæster ind om dagen i dette enorme, marmorbelagte og højloftede kulturpalads bestrøet med statuer og relieffer. ${ }^{16}$

Med kristendommens gennembrud ved kejser Konstantins antagelse af den kristne tro i begyndelsen af det fjerde århundrede, skulle man tro, at den asketiske tanke ville erstatte romerrigets koncept om æsteticering af politikken. Og rigtig nok vendte den oldkristne kirke sig imod gladitorkampene, som det ses i den kristne kirkefader Augustins bekendelser fra omkring år 400, hvor han fortæller om vennen Alypius' omvendelse fra at være blevet fanatisk gladiatorfan til at blive from kristen. Skønt Alypius søgte af frigøre sig fra blodrusen i arenaen, måtte han sande, at det ikke kunne lade sig gøre ved egen kraft, for da gladiatoren faldt, og »hele folket opløftede et $\emptyset$ redøvende råb «, faldt Alypius selv »på en ynkeligere måde end den, ved hvis fald hint råb var opstået... Da han nu så blod, inddrak han grusomhed med det samme... han så, skreg, glødede af lidenskab og tog galskaben med sig hjem. Dog friede Du [Gud] ham ud ved din vældige forbarmende hånd «. ${ }^{17}$

Men efterhånden som den kristne kirke fik fat om flere og flere sjæle, blev der opbygget en blændende liturgi i gudstjenestens kult og i pavedyrkelsen, der på mange måder mindede om den romersk antikke kejserkult. Som kejserne ofte blev ophøjet til guder efter deres $\mathrm{d} \varnothing \mathrm{d}$ og allerede i levende live stod på tærsklen til en sakralisering gennem at være efterkommere af deres guddommeliggjorte forfædre, blev paven opfattet og dyrket som Guds repræsentant på jorden. Jesus blev i den oldkristne tradition fremstillet som den antikke solgud Sol Invictus, som med sit hestespand bevæger sig over himmelrummet, og som var blevet et led i den romerske statsreligion under kejser Aurelian. ${ }^{18}$ Arkitektonisk byggede det kristne kirkebyggeri direkte videre på den romerske basilika og de oktogonale termerum. Romerske templer, med Pantheon i Rom som den i dag bedst velbevarede, kun- 
ne annekteres af den kristne kirkes symbolik. Og paven kunne omdøbe kejser Hadrians Mausolæum til Castel Sant' Angelo med direkte underjordisk forbindelse til Vatikanet. Den romerske $\varnothing$ rn blev udskiftet med den kristne engel. Hvor kejserne havde deres Palatinerhøj med paladserne, fik paven sin Vatikanstat. Og på Peterspladsen fik paven sit eget »forum«, hvor processioner og sang til hans ære kunne finde sted. Som de romerske senatorer var iklædt smukke togaer med farver, der markerede deres stand, kunne pavens kardinaler og det $\emptyset v r i-$ ge gejstlige hierarki kendes på deres farvestrålende dragter.

Med reformationen i 1536 gjorde protestantismen oprør mod hele den udvendige forblændelse i pavestolens gudsdyrkelse. Endnu engang trådte Rom ind på scenen med et æstetisk budskab, der skulle forandre den europæiske kulturhistorie. Katolicismens svar i den såkaldte modreformation var mere æstetik, mere svulstig gudsdyrkelse i barokkens orgelbrus. ${ }^{19}$ Godt nok var den barokke krop ikke som den antikt romerske en kødelig, kæmpende krop, men dramaet og dynamikken, ja selv ekstasen blev nu mere og mere fremherskende i den religiøse kunsts sublimerede kropsdyrkelse.

I kirken Il Gesù (1568-84) i Rom viser roma barocca sig ved, at figurerne i lofter og fra altre simpelthen ikke kan holde sig tilbage, men presser sig fri af rammerne for tredimensionalt at belære os om, hvad der sker med reformationens mørkemænd på deres vej mod helvede. ${ }^{20}$ Og i Sant' Ignazio kirken drives teaterallegorien så vidt, at kuplen i loftet gennem »snyd af øjet«, trompe-l'oeil, giver indtryk af markant dybde, skønt loftet er fladt som en pandekage. ${ }^{21}$ I barokken blev byen omdannet til et æstetisk forførende totalteater. På Capitolhøjen kan man opleve Michelangelos præbarokke totalinstallation fra 1564 med den enorme plads med paladser og kolonner af statuer, hvor selv den kolossale, meditativt appellerende trappe med de lange trin op til paladserne er tænkt med i den scenografiske helhed.

Som paven var Guds stedfortræder på jord, måtte alle mennesker spille deres rolle i det gudgivne stykke og i byens scenografi. Døden var allestedsnærværende, så i den korte tid der var tildelt mennesket, gjaldt det om bedst muligt at spille sin rolle på livets store scene. Operaen og karnevallet blev folkelige udslag af den udadvendte teatralitet. Samtidig med at pavestaten havde et i perioder mildt sagt belastet forhold til den verdslige politik, politiserede Vatikanet selv hæmningsløst ikke mindst på det seksual- og familiepolitiske område.

Efter romersk kejsertid og barok skulle man tro, at Rom havde udlevet sit potentiale for innovativ, politisk æstetik. Men med Benito Mussolinis magtovertagelse i 1922 rykkede fascismen ind på den europæiske scene, og snart bredte ideen om æstetisering af politikken sig til andre lande. Gennem dobbeltheden af forførelse og tvang skulle befolkningen bydes en fascinerende, men også dødsensfarlig sportificering og militarisering af de unge mænd f.eks. gennem det ensrettede ungdomsforbund Balillaen. ${ }^{22}$

Fascismen byggede på, at det dialogiske ord i parlamentet skulle erstattes af $\gg$ ord i sten«. Kort sagt af gigantisk byggeri, der skulle få befolkningen til i bogstaveligste forstand at gå i knæ som ved det enorme og næsten truende neoklassicistiske byggeri Museo della Civiltà Romana i den fascistiske mønsterby og verderdensudstillingsområde EUR udenfor Rom. ${ }^{23}$ Uden for museet står en statue af kejser Augustus, og Mussolini så sig da også som den gen- 


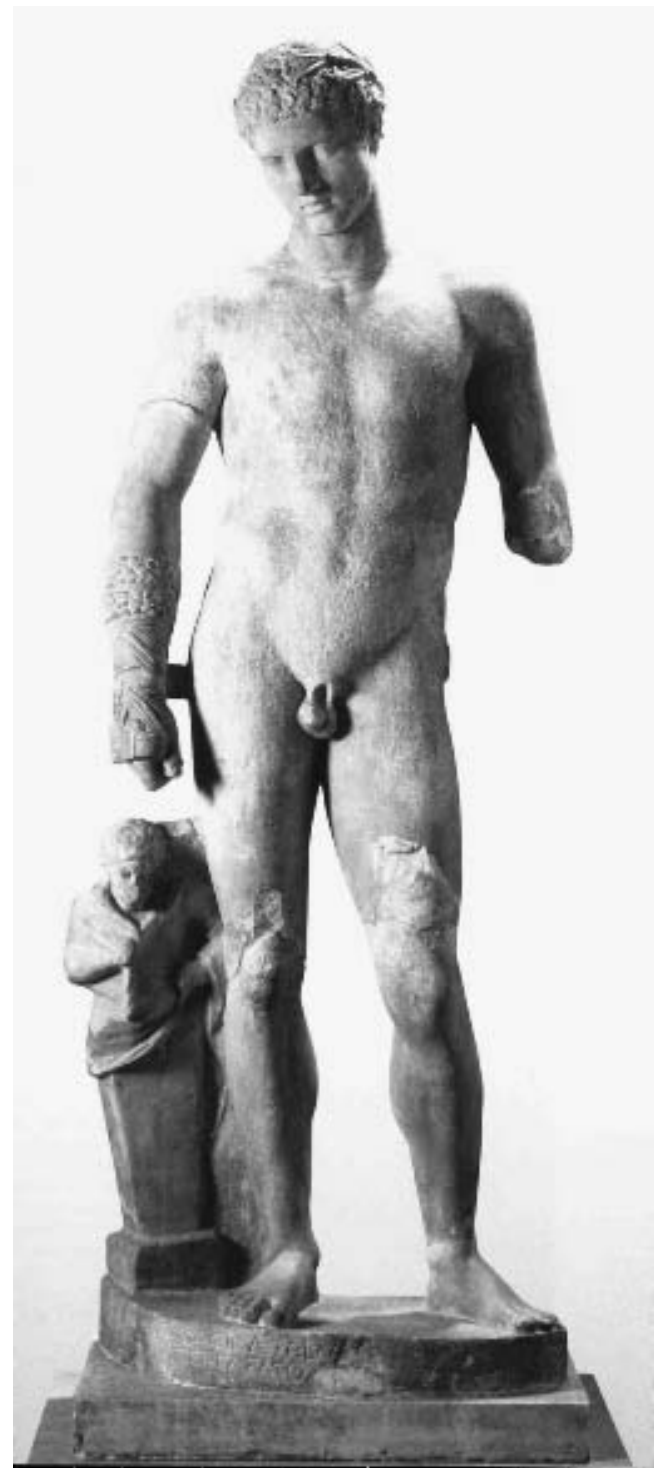

Sejrende bokser. Kransen af olivenblade på hovedet af den unge bokser, viser at han har vundet en boksekamp.

fødte kejser. Ligesom de rigtige kejsere, der demonstrerede deres magt gennem oprettelse af pompøse repræsentationsrum, de såkaldte fora, måtte også »Il Duce« have et $»$ Foro Mussolini«, der i dag ligger helt intakt langs Tiberen i udkanten af
Rom. Her knejser en kejserlig 300 ton fallisk obelisk med titlen Mussolini Dux, Føreren Mussolini, og i relieffer på broen af poleret marmor, der fører til Mussolinis Forum, og i mosaikker som vejbelægning fremstilles den 3. armés glorværdige sejre $\mathrm{i}$ Etiopien (i øvrigt med brug af mindre glorværdig giftgas), hvor grundstenen til det nye imperium skulle lægges. På Foro Mussolini kunne den opmarcherede ungdom hylde deres Fører gennem sportslege på Forummets marmorstadion. Dette stadion var garneret med omkring 60 statuer af overdimensionerede, 4 meter høje, muskelsvulmende krigere, arbejder og sportsmænd, der kunne fremvise de perfekte og krigsduelige legemer som symboler på det Tredje Roms ny kultur, der skulle overstråle caesarernes og pavernes Rom. ${ }^{24}$ Mussolini selv tonede frem som poseurtype med spændte muskler, fremskudt hage og indtrukket bug som macho-ikon og inkarnation af fascismens dynamik som svømmer, rytter, pilot og automobilkører. ${ }^{25}$

Hvor barokken markerede skabelsen af et helt nyt formsprog, blev fascismens vigtigste bidrag til kunsthistorien dens megalomani og koldt retlinede neoklassicisme. Fascismens kvalitative særpræg i arkitekturhistorien blev dens kvantitetsdyrkelse. Fascismen kan ses som et fors $\varnothing \mathrm{g}$ på en reromanisering af det italienske folk, men i tragisk lys, da fascismens maskuline voldsæstetik og etiske lovløshed så helt bort fra det oprindelige romerske retfærdighedsbegreb symboliseret i gudinden Justitia. ${ }^{26}$

I dag kan man frygte, at der går en rød tråd fra Caesar til Silvio i romersk historie. Den italienske ministerpræsident Silvio Berlusconi har ikke kun samlet den politiske magt og mediemagten, men er også gået på strandhugst på dommernes domæne. Hans TV-programmer tilbyder en uendelig række af glamourpersoner og garderhøje 
falske blondiner, der med strålende øjne og naive spørgsmål gør hverdagen lettere for mangen en italiensk skabsmacho. Skuespil fremfor politisk dialog. Hans retoriske evner overbeviser ikke EU-politikerne, men fænger tilsyneladende hos mangen en lidenskabelig italiener med hang til store armbevægelser frem for små mundbevægelser. Hvor Caesars forfængelighed viste sig $\mathrm{i}$ hans legendariske hentehår, sørger Berlusconis retouchører for at give ham hår på hans skaldede isse, når han er blevet fotograferet bagfra, og nu har han endog fået transplanteret nyt hår.

Samtidig har han skabt sit eget »Foro Berlusconi i A.C. Milans fodboldkompleks, der udgør en betragtelig populistisk magtbase for dets ejer. Her skal man huske, at den italienske fodboldkultur altid har været stærkt politiseret og center for politiske hvervekampagner ikke mindst gennem de såkaldte Ultràs, hooligans, der bekender sig til ekstremerne fra begge sider af det politiske spektrum. ${ }^{27}$ Berlusconis fodboldstrategi kan ses som et fors $\emptyset \mathrm{g}$ på at etablere et nærmest gammelromersk patron-klientforhold, hvor masserne tilbydes skuespil og regionale sejre til gengæld for politisk loyalitet: »Din sejr, vor støtte«.

\section{Noter}

1 West, D.M., Celebrity Politics, Prentice Hall, 2002.

2 Jvf. Ørsted P., Gajus Julius Cæsar, Kbh., 1994.

3 Dupont F., Daily Life in Ancient Rome, London, 1994.

4 Ørsted, s.90ff.

5 Op.cit., s.16.

6 Köhne E., og Ewigleben, C. (red.), Gladiators and Caesars, s. 16ff samt Ørsted, s.161f.

7 Jvf. Nielsen S. og Mathiesen H.E. (red.), Rom en antik storby, Århus, 1991, s.14ff samt Köhne og Ewigleben, s.17ff.

8 Jvf. Köhne og Ewigleben s.139.
Milans sejr i Champions League i 2003 regnes således med at have flyttet $\mathrm{i}$ hundredtusindvis af vælgere over mod Berlusconis højrekoalition. Ironisk nok var det præcis Berlusconis angst for, at operapublikummet i Veronas gamle gladiatorarena skulle vende sig imod ham, der i 2003 fik ham til at melde afbud til forestillingen på Aida, som han skulle have set sammen med kansler Schröder. Og at Berlusconi tager ideen om samfundet som scene ganske seriøst ses i hans debut som kærlighedssangskriver på $\mathrm{CD}$, der bringer mindelser om kejser Neros patetiske forsøg på at vinde de af ham fremtvungne sangkonkurrencer ved de olympiske lege, hvor han i $\varnothing$ vrigt også vandt i hestevæddel $\varnothing b$, sk $\varnothing n t$ han væltede og aldrig nåede frem til målstregen. ${ }^{28}$

Vil Italien endnu engang blive toneangivende $i$ teatraliseringen af det politiske liv i Europa nu med den italienske formand for EU i spidsen og med hans erklærede forståelse for Mussolinis »humane fascisme «? Forhåbentlig markerer Silvios og Schwarzeneggers gennembrud ikke det 21 . århundredes revolutionære bud på en fornyet æstetisering af politikken.
9 Jvf. Mumford L., The City in History, London, 1961.

10 Jvf. The Penguin Historical Atlas of Ancient Rome, London, 1995, s.82f.

11 Jvf. Köhne og Ewigleben s.26ff.

12 Jvf. Nielsen S. og Mathiesen, s.14.

13 Jvf. Plinius den yngre, Epistulae IX,6.

14 Jvf. Köhne og Ewigleben s.26.

15 Cameron, A., Circus Factions. Blues and Greens at Rome and Constantinople, Oxford, 1976.

16 Jvf. Cappelli, R. (red.), The Baths of Caracalla, Soprintendenza Archeologica di Roma, Milano, 1998. 
17 Jvf. Augustin, Confessiones, VI 8,13.

18 Jvf. Nielsen og Mathiesen, s.189.

19 Jvf. Nykjær, M., I pavernes Rom, Kbh., 2004.

20 Ridolfini, C.P., Roma - Chiesa del Gesù, Rom, 1997.

21 Jvf. Nykjær, s.303ff.

22 Bosworth, R.J.B., Mussolini, London, 2002, s. 145 og 237.

23 Museo della Civiltà Romana, Romamus EUR, Comune di Roma, 1999.

\section{Litteratur}

Augustin, Confessiones, VI 8,13.

Bosworth, R.J.B., Mussolini, London, 2002.

Cameron, A., Circus Factions. Blues and Greens at Rome and Constantinople, Oxford, 1976.

Cappelli, R. (red.), The Baths of Caracalla, Soprintendenza Archeologica di Roma, Milano, 1998.

Dupont F., Daily Life in Ancient Rome, London, 1994.

Frandsen, S.B., Det tredje Rom, Tidsskriftet Sfinx, 1991.

Köhne E., og Ewigleben, C. (red.), Gladiators and Caesars, London, 2000.

Mumford L., The City in History, London, 1961.

Museo della Civiltà Romana, Romamus EUR, Comune di Roma, 1999.
24 Frandsen, S.B., Det tredje Rom, Tidsskriftet Sfinx, 1991.

25 Bosworth, s.270 a-p.

26 Ørsted, s.122ff.

27 Podaliri, C. og Balestri C., The Ultras, Racism and Football Culture in Italy i: Brown, A., Fanatics, London 1998, s. 88-100.

28 Jf. Ørsted, P., Nero - Kejser i Rom, Kbh., 2004.

Nielsen S. og Mathiesen H.E. (red.), Rom - en antik storby, Århus, 1991.

Nykjær, M., I pavernes Rom, Kbh., 2004.

Ørsted P., Gajus Julius Cæsar, Kbh., 1994.

Ørsted, P., Nero - Kejser i Rom, Kbh., 2004.

Podaliri, C. og Balestri C., The Ultras, Racism and Football Culture in Italy i: Brown, A., Fanatics, London 1998.

Ridolfini, C.P., Roma - Chiesa del Gesù, Rom, 1997. The Penguin Historical Atlas of Ancient Rome, London, 1995.

West, D.M., Celebrity Politics, Prentice Hall, 2002. 